\title{
INTERACCIONES E IMPLICACIONES ENTRE FILOSOFÍA Y EDUCACIÓN ${ }^{1}$
}

Gonzalo Morales Gómez Ph-D.

\begin{abstract}
Esta ponencia presenta de forma sucinta las múltiples interacciones e implicaciones entre la Filosofía y la Educación de la "era planetaria", mostrando la enorme importancia y urgencia del tratamiento epistemológico y hermenéutico de las teorías, los problemas y las prácticas educativas y pedagógicas en el momento actual de la cultura occidental y en el horizonte de precomprensión latinoamericano y caribeño. Se pone de relieve, así mismo, el inmenso valor de los aportes y cuestionamientos de la educación a la filosofía contemporánea, que hacen de ésta la "socia (no ancilla) pedagogiae".
\end{abstract}

\section{INTRODUCCIÓN}

\section{1 ¿Qué es filosofar en perspectiva educativa?}

"Creo que el individuo, al que es preciso educar, es un individuo social, y que la sociedad es una unión orgánica de individuos. Si removemos del niño el factor social, sólo nos queda una abstracción: si de la sociedad 
removemos el factor individual, no nos queda otra cosa que una masa inerte y sin vida. Por eso la educación debe partir de una comprensión psicológica de las capacidades, intereses y hábitos del niño. Y en cada uno de sus pasos se tiene que gobernar por referencia a esas mismas consideraciones. Esas capacidades, esos intereses y hábitos deben ser objeto de interpretación continua; es preciso que sepamos lo que significan. Y se los tiene que traducir en los términos de sus equivalentes sociales, en los términos de lo que pueden lograr en orden a un servicio social" (John Dewey, My Pedagogic Creed, 1987).

En el credo pedagógico de Dewey encontramos tres palabras claves para entender el papel de la Filosofía en la Educación, a saber: comprensión, interpretación, significación.

La comprensión nos remite a la reflexión, la interpretación a la crítica y la significación al sentido.

El filosofar es un ejercicio mental de reflexión sobre realidades fácticas (cosas y acaecimientos) y realidades existenciales (personas y acontecimientos), una de las cuales es justamente la educación, que trata de teorías y métodos, por una parte, y de interrelaciones humanas, por otra. De dicho ejercicio mental resultan filosofías de la educación, es decir, maneras plurales de concebir y realizar el acto de educar. Dewey, por ejemplo, en el texto citado, esboza en su "credo pedagógico" una filosofía educativa expresada así: "Creo que el individuo al que es preciso educar es un individuo social, y que la sociedad es una unión orgánica de individuos".

El filosofar es también un ejercicio mental de crítica, es decir, de discernimiento y validación de argumentos, posiciones, hipótesis, modelos y metodologías diversas, realizadas según criterios de racionalidad múltiple y estudio de contextos específicos de índole sociocul- 
tural. En el texto de Dewey aparece este aspecto en la siguiente declaración: "por eso la educación debe partir de una comprensión psicológica de las capacidades, intereses y hábitos del niño".

El filosofar, finalmente, es un ejercicio mental de dar sentido al pensar, al actuar y al vivir cotidiano, entendido como establecer los fundamentos y la dirección del pensamiento y de la actividad humana. Es lo que manifiesta Dewey casi al inicio de su credo: "Si removemos del niño el factor social, sólo nos queda una abstracción; si de la sociedad removemos el factor individual, no nos queda otra cosa que una masa inerte y sin vida".

\section{2 ¿Qué es educar en perspectiva filosófica?}

"El hombre que la educación debe plasmar dentro de nosotros no es el hombre tal como la naturaleza lo ha creado, sino tal como la sociedad quiere que sea" (Durkheim).

La educación -cualquiera sea su enfoquedepende sustancialmente de la visión de la naturaleza humana que se tenga y de los "fines de la educación" que se persigan.

Ambos aspectos son elementos filosóficos, enmarcados normalmente en una concepción peculiar de la historia y en intereses ideológicos de una cultura. Como lo advierte Eisner (1998) hablando de la educación norteamericana: "Hoy las nuevas demandas cognitivas del trabajo y las exigencias de los empleos son las fuentes fundamentales de datos para formular las intenciones educativas y elaborar los programas escolares". O como lo denuncia Maturana (1997) en el caso de la educación chilena y latinoamericana: "Ya no se educa a los niños para que sean seres íntegros [...], sino para prepararles para el mercado laboral". 
La educación exige un telos, una finalidad, que se concentra en un perfil deseado de hombre o mujer, en un ideal de vida o en un proyecto de sociedad, para lo cual se requiere poseer un conocimiento adecuado del ser humano que ha de ser educado y una claridad meridiana en los principios que han de orientar dicha educación. dad y fundamento.

La educación exige, pues, lucidez, intencionali-

\section{FILOSOFÍA Y EDUCACIÓN}

En el decurso histórico de la cultura occidental, la Filosofía y la Educación han caminado juntas, inicialmente dependiendo mucho la Pedagogía de la Filosofía y después desvinculándose poco a poco de la tutela de ésta hasta alcanzar nuevamente una posición de importancia en la actualidad.

\subsection{Interacciones}

\subsubsection{Filosofía e Historia de la Educación}

Desde la Grecia clásica hasta los comienzos del Racionalismo y la Revolución Científica, la Filosofía contribuyó poderosamente a la elaboración de las primeras ideas pedagógicas.

Platón fue el primer filósofo en elaborar una filosofía de la educación enmarcada en su teoría política y ésta a su vez en su sistema filosófico general, el idealismo, que surgió como reacción ante la práctica educativa desarrollada por los sofistas orientada a satisfacer las necesidades del saber-hacer político del nuevo grupo con poder económico que aparece al lado de la casta aristocrática en Atenas. Esta concepción idealista de la educación será elaborada mucho más tarde por Rousseau, Kant y Herbart. 
Con la aparición del Racionalismo de Descartes y Bacon (siglos XVI y XVII), seguido del desarrollo acelerado de las ciencias naturales en los siglos XVII y XVIII, se instaura en Occidente la hegemonía del conocimiento científico y del realismo filosófico (pragmatismo, materialismo) y con ello la exigencia de convertir a la Educación y la Pedagogía en ciencias experimentales. La pedagogía empieza entonces a fundamentarse más en las ciencias humanas (psicología, sociología, medicina, lingüística) que en la Filosofía. Comenio, Pestalozzi, Montessori, Decroly y Dewey forman parte de esta corriente.

En los Siglos XIX y XX se consolida la concepción tecnocrática de la ciencia y con ella la manipulación política de la Educación y la Pedagogía puestas al servicio de intereses creados distintos de la verdad.

En las dos últimas décadas del siglo XX y en lo que va corrido del siglo XXI, la Filosofía ha vuelto a adquirir especial importancia en la Educación y la Pedagogía a través, especialmente, de la Epistemología, la Filosofía de la Educación y el Pensamiento Complejo, como saber estructurador y totalizador, garante del orden, la coherencia y la consistencia entre la multiplicidad de datos de las ciencias y, en particular, de las ciencias de la educación.

Cabe destacar el hecho de que a lo largo de la historia de la Educación y la Pedagogía, la Filosofía ha cumplido una función humanizante de primer orden en cuanto que ha hecho tomar conciencia al ser humano y a la sociedad de su situación histórica de dependencia o de libertad, de absolutismo o relativismo, de reduccionismo o integralidad en sus planteamientos educativos. 


\subsubsection{Filosofía de la Educación}

Si la filosofía como tal es un "saber reflexivo y crítico sobre el sentido último de la totalidad de lo real" (M. García Amilburu), la Filosofía de la Educación es una reflexión radical sobre los supuestos profundos de la educación, que dan claridad, coherencia, discernimiento y dirección a la acción educativa. Relaciona los conceptos pedagógicos fundamentales con los principios básicos de otras ciencias y de la Filosofía, y busca comprender el fenómeno educativo de manera holística. No pretende tanto generar nuevos conocimientos como proporcionar una mejor y más profunda comprensión de lo ya conocido.

Esos "supuestos profundos" antes mencionados se refieren no sólo a principios, sino también a conceptos fundamentales en Educación, tales como formación, aprendizaje, educabilidad, libertad, autoridad, disciplina, creatividad, etc.

La Filosofía de la Educación no debe confundirse con: Filosofía para educadores (antologías de cuestiones filosóficas), Estudio metafísico aplicado a la educación (ontología de la realidad educativa), Deducciones lógicas educativas de los grandes sistemas filosóficos, Estudio de los principios filosóficos de la educación. La Filosofía de la Educación parte del principio de que educar es ayudar a un ser humano a "comprender la complejidad de la totalidad de su ser" (Krishnamurti), lo cual implica una Antropología de la Educación, es decir, un estudio profundo de la naturaleza humana y de sus posibilidades de desarrollo.

Educar es también "depositar en cada hombre toda la obra humana que le ha antecedido; es hacer a cada hombre resumen del mundo viviente, hasta el día en que vive; es ponerlo al nivel de su tiempo, para que flote sobre él, y no dejarlo debajo de su tiempo, con lo que no podrá 
salir a flote; es preparar al hombre para la vida" (José Martí).

En definitiva, la Filosofía de la Educación busca, con la ayuda de la Antropología Filosófica, integrar los saberes sobre el ser humano en una síntesis coherente y comprensiva, que le permitan a éste "florecer desde su propia naturaleza intrínseca” (Osho).

Por todo lo expuesto, se puede concluir que todo proyecto educativo bien construido deberá contar con una "filosofía educativa" que le dé sustento y dirección.

\subsection{Implicaciones}

\subsubsection{Epistemología de la Pedagogía}

La Epistemología o Filosofía de la Ciencia es la disciplina que establece los fundamentos y criterios de validez del conocimiento y la investigación científica. La Epistemología de la Pedagogía es una "epistemología regional”, según la clasificación de Piaget, que se ocupa del estudio de los supuestos lógicos y las condiciones de posibilidad y validez de los conocimientos, métodos y resultados de las ciencias de la educación y de las ciencias humanas relacionadas con ellas, y en particular, de la pedagogía. Tareas importantes de una epistemología de la educación y la pedagogía son:

a) Definir el objeto de la educación y la pedagogía

b) Formular teorías de la educación

c) Establecer los fines de la educación

d) Validar teorías, modelos y métodos educativos, curriculares y pedagógicos.

e) Plantear preguntas fecundas para el fortalecimiento de las relaciones entre Filosofía y Educación, tales como: 
1. ¿Qué concepción o teoría filosófica debe fundamentar la construcción de una autentica pedagogía?

2. ¿Qué importancia tiene para la formación de los nuevos educadores el principio establecido por Kurt Lewin: "La mejor práctica es una buena teoría"?

3. ¿Deben la Educación y la Pedagogía independizarse de la Filosofía, superando toda forma de simple interpretación, para pasar definitivamente al campo de la observación, descripción y explicación del hecho educativo a través de la investigación empírica?

4. ¿Cualquier modelo o enfoque curricular puede ser congruente con la educación católica?

Como ilustración de lo anterior me permito transcribir de forma sintética dos ensayos epistemológicos personales sobre un tema de Filosofía Educativa (tema A) y otra de Pedagogía (tema B):

\section{TEMA A: Amor y conocimiento}

Antes de indicar de qué modo el amor es forma del conocimiento, es indispensable aclarar -al menos en términos generales- qué se entiende por "conocimiento" y qué por "amor".

El conocimiento o capacidad comprehensiva es un dinamismo del hombre que le permite aprehender, transformar y trascender la realidad interior y exterior a él.

El amor o capacidad comunicativa es otro dinamismo del hombre que le posibilita comunicarse, fusionarse y darse a la realidad interior y exterior a él. 
Ambos, el dinamismo del conocimiento y el dinamismo del amor, constituyen el único dinamismo del ser, que es "ser-en-sí" (conocimiento) y "ser-para-otro" (amor).

Tan intrínseca es esta estructura al ser que el "ser-en-sí" no puede aprehender, transformar ni trascender nada hasta que no encuentra un objeto, es decir, un ob-iectum: algo lanzado delante de sí, que le obliga a convertirse en "ser-para-otro".

En este sentido el "ser-para-otro" constituye el fundamento de posibilidad para el "ser-en-sî". Dicho de otro modo, comunicarse, fusionarse y darse es una exigencia ontológica del "ser-en-sí" para poder afirmarse como "en sí".

Ahora bien, esta estructura no corresponde únicamente al ser subjetivo (realidad interior), sino también al ser objetivo (realidad exterior), en cuanto que las cosas mismas están ahí para "ser-conocidas" (este es su "ser-ensí) y para "ser asumidas" (este es su "ser-para-otro"). La disponibilidad es una dimensión constitutiva del ser real. De modo que así como existe una racionalidad del hombre, existe también una racionalidad de la naturaleza (la lógica de la materia y de la vida); y si se da el amor en el hombre se da también en la naturaleza (finalidad e intencionalidad de las cosas).

El amor está, pues, en la base del mundo personal e impersonal. La destinación esencial de las cosas a otra realidad distinta de ellas, constituye el amor como núcleo del ser de las cosas. Las cosas son en cuanto están dadas, ya que son don en virtud de que han recibido de otra realidad la existencia; en sí mismas no son autofudantes, sino heterofundadas.

En el ámbito personal, el amor es, en definitiva, la profundidad de la razón misma, en cuanto movimien- 
to excéntrico del ser. Tillich lo insinúa en este párrafo: "La profundidad de la razón es la expresión de algo que no es la razón, sino que le precede y se manifiesta a través de ella. La razón, tanto en su estructura objetiva como en su estructura subjetiva, apunta hacia algo que aparece en estas estructuras, pero que las trasciende en poder y significación (....) Esta dimensión de la razón, la dimensión de profundidad, es una cualidad esencial de todas las funciones racionales". Es esa profundidad la que hace del amor la forma del conocimiento, como lo ha expresado Karl Rahner en su libro "Oyente de la Palabra": "En el centro y núcleo del conocimiento se halla el amor, del que vive el conocimiento mismo".

El amor nutre al conocimiento en el sentido de que dispone el espíritu para la búsqueda y encuentro de "lo otro": "lo objetivo", en lo que radica precisamente la esencia del conocer humano. Y hace que lo otro siga siendo otro, a pesar de apropiárselo y reducirlo a la unidad de la conciencia: "El amor es lo que supera las categorías de la objetividad y realiza efectivamente la esencia de la vida manteniendo la diferencia en la unidad" (J. M. Rovira). Es lo que Hegel llamó "el milagro del amor", que evita la dispersión del conocimiento y el atropello a la realidad: "El amor es ese milagro por medio del cual lo que es dos se convierte en uno, sin que ello conduzca a la completa supresión de la dualidad".

TEMA B: Paradigmas, modelos, enfoques, corrientes y tendencias pedagógicas

En el lenguaje educativo comúnmente utilizado por docentes, investigadores y escritores de todo el mundo no se establece una diferenciación estricta entre paradigmas, enfoques, modelos, corrientes y tendencias pedagógicas, usados indistintamente para hacer referen- 
cia a la educación en general y estrechamente ligados a la evolución de la Psicología como ciencia en diferentes ramas. Existe sin embargo un uso más riguroso de la terminología en aquellos educadores e investigadores más familiarizados con la Filosofía de la Educación y la Epistemología de la Pedagogía.

Siguiendo un orden de frecuencia en el uso de estos términos, se escucha más a menudo la expresión corrientes pedagógicas, seguida de modelos pedagógicos, enfoques curriculares, tendencias pedagógicas y paradigmas educativos. Todo parece depender de la profesión de quienes utilizan estos vocablos. Así, por ejemplo, los psicólogos prefieren hablar de corrientes; los epistemólogos de enfoques y paradigmas; los sociólogos e historiadores de tendencias, y los pedagogos de modelos.

Auscultando más a fondo los diferentes contextos en los que se emplea uno u otro término, así como el uso metalingüístico de cada uno de ellos, se pueden percibir diferencias y distinciones que enriquecen el lenguaje educativo y la espesa selva de propuestas educativas variopintas de las que da buena cuenta una somera consulta en la Internet. Cabe advertir, no obstante, que no es posible en modo alguno introducir distinciones absolutas en esta terminología, sino tan sólo señalar acentos y matices, que permiten apreciar las variadas tonalidades de la pedagogía y degustar los diversos sabores de la educación.

\section{PARADIGMAS}

Según Thomas S. Kuhn, un paradigma es "una constelación global de convicciones, valores y comportamientos compartidos por los miembros de una determinada comunidad". Esta constelación se convierte poco a poco en un sistema de creencias o de "reglas y reglamentos" (J. Barker) aceptados como verdaderos, que dirigen el 
pensamiento y la acción de individuos y grupos a modo de referentes históricos, culturales y sociales. Un paradigma alcanza su madurez cuando se incorpora como engrama en el cerebro de muchas personas o se vuelve un "inconsciente colectivo" en un amplio sector de la población. En resumen: los paradigmas son sistemas de ideas o creencias compartidos por un grupo determinado como verdaderos mientras aparece otro sistema capaz de sustentar su propia validez. Ejemplos: la creencia en el destino, la concepción positivista de la ciencia, la calidad de los relojes suizos.

- Un paradigma se conoce básicamente por las siguientes características:

- Es una idea(as), creencia(s) o comportamiento(s) arraigados y aceptados a priori como verdaderos.

- Lo comparte una comunidad con un número elevado de miembros.

- Se forma generalmente en un período considerable de tiempo.

- No es fácil de cambiar por otro nuevo debido a la resistencia que genera.

- Puede tener un sustento teórico o ideológico.

En Pedagogía, se suele aplicar el término paradigma a un enfoque, modelo o corriente pedagógica que goza o ha gozado de amplia aceptación y aplicación en un sistema educativo socialmente reconocido. Por ejemplo, la educación tradicional o bancaria y la tecnología educativa. El constructivismo empezó como corriente, luego pasó a ser modelo y en la actualidad se ha convertido en un paradigma. 


\section{ENFOQUES}

Un enfoque es una manera de concebir, organizar y realizar la educación y el aprendizaje, que puede dar origen y fundamento a distintas corrientes y modelos pedagógicos. Los enfoques provienen normalmente de teorías construidas por psicólogos, sociólogos o investigadores educativos de gran nombre, a partir de las cuales se hacen interpretaciones y se formulan criterios, lineamientos, políticas y estrategias pedagógicas. Los enfoques son por principio concepciones y percepciones abiertas, flexibles e hipotéticas de la realidad educativa, que permiten ajustes, adaptaciones e integraciones de distintas ciencias y de diferentes experiencias pedagógicas, conservando siempre una perspectiva idiosincrásica en el análisis del fenómeno educativo.

Un típico ejemplo es el enfoque cognitivo o cognitivista basado en la psicología genética de Piaget, Dewey, Wallon y Merani, que dio origen posteriormente a las corrientes y modelos constructivistas de Bruner, Ausubel, Novak, Porlán, Carretero, Flórez y Batista, entre otros, y al conexionismo de Edelman y Sylwester. Un caso singular es el de L.S. Vygotsky, quien por haber sido compañero de investigación de J. Piaget, creó como éste un nuevo enfoque pedagógico, a saber, el enfoque histórico cultural, pero al mismo tiempo, en cuanto pensador independiente de Piaget, dio origen también a un nuevo modelo pedagógico: el constructivismo social.

Otros enfoques importantes son: el enfoque escolanovista de Dewey, Decroly, Claparede, Montessori, Freinet y Agustín Nieto Caballero, más conocido como escuela nueva; el enfoque conductista de Skinner, que fue más bien una teoría psicológica que hizo surgir más tarde los modelos instruccionales de Tyler, Bloom, Gagné y Merrill; el enfoque sistémico de Bertalanffy, que ha dado 
lugar a la aparición de diseños globales de educación (Banathy, Colom, Figueras, Hernández). Otros enfoques: humanista, holístico, hermenéutico, problémico, sociocrítico, ecológico - contextual.

Un enfoque se identifica generalmente por los siguientes rasgos distintivos:

- Se fundamenta en una teoría científica, casi siempre psicológica, construida mediante investigación.

- Es una propuesta singular, pero al mismo tiempo abarcadora, con distintos grados de amplitud sobre la forma como se debe educar al ser humano, que incluye concepciones, principios, políticas y estrategias para el diseño y la administración del currículo.

- Es una perspectiva abierta, flexible e hipotética, que permite reformulaciones y reajustes sobre la marcha. Evidentemente que hay enfoques más abiertos que otros, como por ejemplo el humanista y el holístico.

- Da origen a modelos y corrientes pedagógicas independientes.

En pedagogía, los enfoques son especialmente importantes para la construcción de proyectos educativos institucionales porque les dan a éstos mayor direccionalidad y solidez que los modelos pedagógicos, dado que los enfoques son por lo regular más estables y duraderos, mientras que los modelos son más variables y transitorios.

\section{MODELOS}

Un modelo es un esquema o patrón representativo de una teoría psicológica o educativa. Los modelos educativos son entonces formas histórico -culturales de concreción o materialización de un enfoque, una corriente o un paradigma. Esto los hace más cerrados, limitadores y encasilladores. 
En efecto, los modelos se centran más en los aspectos curriculares de la educación dando especial relieve a una dimensión o componente de la formación o el aprendizaje, en torno al cual se hace girar todo lo demás. Por ejemplo, la componente "integración", de donde resultan modelos pedagógicos como la síntesis integradora de Rafael Porlán o los proyectos curriculares integrados de Jurjo Torres, o las construcciones curriculares alternativas de Nelson López. Otra componente puede ser la vinculación de la teoría con la práctica, que da lugar a la educación dual y a la educación experiencial. Son ya clásicos en la historia de la Pedagogía el modelo tradicional, centrado en objetivos, y el modelo naturalista, centrado en la libertad y la espontaneidad de los alumnos.

Un modelo pedagógico se diferencia de otras formas educativas por los siguientes aspectos:

- Es más concreto y cerrado que un enfoque.

- Se deriva normalmente de un enfoque pedagógico, aunque también puede proceder de una corriente o de una tendencia pedagógica.

- Está más orientado a la propuesta curricular que a la concepción educativa.

- Pierde vigencia con mayor rapidez, a menos que se transforme en un paradigma o se sustente en un enfoque de gran fortaleza científica.

- Se resiste a la integración con un modelo diferente.

En Pedagogía, los modelos representan la mayor parte de las propuestas curriculares que encontramos a menudo en la literatura pedagógica. Se les denominan modelos para indicar que se toman como patrones o pautas del accionar educativo institucional. Sin embargo, son más coyunturales que estructurales debido a que respon- 
den más a demandas sociales (necesidades e intereses de un colectivo) que a descubrimientos científicos (investigación educativa).

\section{CORRIENTES}

Una corriente es una línea de pensamiento pedagógico, con carácter innovador, que se encuentra en proceso de investigación, sistematización y validación. Las corrientes son tendencias fuertes en educación, que no tienen todavía la estructuración de un modelo, ni la fundamentación de un enfoque ni la amplitud de un paradigma, pero van ganando adeptos entre los educadores y creando escuela propia.

Las corrientes pedagógicas son de varios tipos

a) Radicales, cuando proponen cambios profundos en el sistema educativo o en la teoría curricular; por ejemplo, la pedagogía liberadora, el romanticismo pedagógico y la pedagogía personalista.

b) Moderadas, cuando pretenden solamente mejorar un aspecto particular de la concepción o la práctica pedagógica; por ejemplo, el neoconductismo y la educación por proyectos.

c) Innovadoras, cuando ofrecen nuevas alternativas en educación; por ejemplo, la educación para la convivencia, basada en la Biología de la Educación, o la pedagogía autogestionaria.

Una corriente se caracteriza por los siguientes rasgos:

- No tiene una estructura curricular bien definida

- Está en proceso de experimentación

- Atrae seguidores, sobre todo entre los intelectuales 
- Sirve de base a algunos modelos pedagógicos

- Es más coyuntural que estructural mientras deviene en modelo o enfoque.

En Pedagogía, las corrientes estimulan la investigación educativa y sientan las bases de futuros modelos, enfoques y paradigmas. Surgen casi siempre como producto de cambios sociales y científicos importantes. Tienen el peligro de convertirse en modas o en ideologías absolutistas. Las corrientes son de utilidad ante todo para la formación epistemológica de los docentes, pero no conviene emplearlas como cimiento de los proyectos educativos institucionales, debido a su transitoriedad y poca estructuración.

\section{TENDENCIAS}

Una tendencia es un impulso, una aspiración, un deseo, una inclinación hacia algo. En educación, la tendencia es una nueva perspectiva educativa que complementa, refuerza o modifica un paradigma, un enfoque, un modelo o una corriente pedagógica. En sus inicios es más débil que una corriente, pero puede desarrollarse más rápido que ésta debido a su fuerte raigambre sociocultural. Las tendencias expresan las demandas sociales en materia de educación y los avances más significativos en las investigaciones educativas de punta. Ejemplos: la autogogía, la hodogogía, la neurogogía, la infogogía, la pedagogía cuántica, la pedagogía sinérgica y la pedagogía de género.

Una tendencia se descubre fácilmente porque:

- No tiene tradición ni posicionamiento pedagógico

- Es más un proyecto a mediano y largo plazo que una realidad inmediata

- Pertenece a la investigación prospectiva 
- Está sectorizada en grupos o países

- Le falta mayor sustento teórico y validación práctica.

En Pedagogía, las tendencias permiten actualizar permanentemente el currículo y responder mejor a los retos sociales y científicos. Abren nuevas líneas de investigación educativa y son un semillero de futuros enfoques y modelos pedagógicos.

\section{CONCLUSIÓN}

Tendencias, Corrientes, Modelos, Enfoques y Paradigmas en Pedagogía son formas naturales de evolucionar y manifestarse históricamente la Educación, que permiten la creatividad y la innovación continuas, así como la renovación permanente de las instituciones educativas.

Como fenómeno cultural, su aparición obedece al hecho de que la Pedagogía cambia de acuerdo a tres factores mutuamente implicados, a saber: la investigación pedagógica como tal, los nuevos descubrimientos científicos y las transformaciones sociales. Casi siempre es el último factor el que estimula al primero y condiciona al segundo.

El estudio de las diferencias esenciales entre tendencias, corrientes, etc., posibilita, además, hacer una validación más rigurosa de las distintas ofertas educativas, curriculares y pedagógicas que a diario nos solicitan, sabiendo que la elección de cualquiera de ellas determina fundamentalmente la orientación, la puesta en marcha y la evaluación de los respectivos proyectos educativos institucionales adoptados o construidos.

Finalmente, cabe recordar que, en la actualidad, este tema parece no haber sido estudiado con la suficiente amplitud y profundidad, por lo cual se requieren aún otras 
investigaciones sobre el particular. El presente artículo quiere ser solamente una primera contribución a tal fin.

\subsubsection{Hermenéutica educativa}

La Hermenéutica es "el arte de interpretar las intenciones y los sentidos más globales y profundos de conversaciones, diálogos y textos que giran en torno, o son respuestas a preguntas" (R. Flórez).

Tal interpretación está lógicamente incardinada en un medio sociocultural. Por eso la Filosofía toma como punto de partida el lenguaje corriente, el sentido común y la evidencia empírica o intelectual, que son en sí mismos constructos culturales. Esto no significa, sin embargo, que la Filosofía tenga necesidad de realización práctica en la forma de una determinada cultura; basta con que un sistema filosófico se halle reflexiva y críticamente fundado y sea coherente en sí mismo. El énfasis hermenéutico de la educación y la pedagogía contemporáneas resulta del hecho de que los acontecimientos educativos los generan e interpretan grupos de personas que dialogan acerca de la vida, comparten saberes y transan significados, buscando consensos como fondo e intencionalidad. Esto les exige validar conceptos e interpretaciones de acuerdo a ciertos criterios de confirmación y de verdad establecidos de forma argumentada.

Ejemplos de criterios permanentes de validación epistemológica son los mencionados por Rafael Flórez Ochoa (1999):

Todo modelo, estrategia, diseño y acción educativa válida en pedagogía se produce como respuesta a una pregunta: ¿cómo contribuye a la formación humana del alumno? 
Cada diseño, currículo y acción educativa necesita ser constantemente recontextualizada desde las partes hasta el todo y del todo hasta las partes. Esta totalidad abarca una recomprensión desde tres globalidades: la formación integral del alumno, el entorno del alumno y la teoría pedagógica que lo inspira.

La interacción teoría-praxis necesita replantearse y cuestionarse de forma permanente en pedagogía, porque la acción pedagógica, diseñada y configurada por estrategias y conceptos pedagógicos, resulta invalida y refutada, cuando en la praxis que configura no contribuye efectivamente al desarrollo y formación humana de los alumnos.

\section{EDUCACIÓN Y FILOSOFÍA}

La Educación como tal incluye también la Filosofía, en cuanto le plantea a ésta preguntas que requieren indagaciones profundas y en cuanto ciertos temas educativos y pedagógicos tienen implicaciones filosóficas.

\subsection{Interacciones}

\subsubsection{Fines de la Educación}

La educación es una actividad teleológica o intencional, es decir, está orientada hacia la consecución de unos fines explícitos e implícitos. Al tratarse de una pluralidad de fines, éstos deberán estár jerarquizados, por ejemplo, en fines inferiores o inmediatos y fines superiores o últimos. Esto es importante, porque a la hora de establecer el currículo concreto hay que hacerlo teniendo en cuenta los fines que se persiguen. Eisner y García Amilburu presentan sendas listas de los fines de la educación propuestos por distintos autores y escuelas: 


\begin{tabular}{|l|l|}
\hline \multicolumn{1}{|c|}{ ELLIOT EISNER } & MARIA GARCÍA AMILBURU \\
\hline 1. Formación en valores & $\begin{array}{l}\text { 1. Conocimientos básicos para vivir en } \\
\text { sociedad. } \\
\text { 2. Iniciación social (hábitos, normas, valo- } \\
\text { res, etc.) } \\
\text { 3. Desarrollo de capacidades. }\end{array}$ \\
$\begin{array}{l}\text { 2. Transmisión cultural } \\
\text { 3 Sensibilización socio- } \\
\text { crítica. } \\
\begin{array}{l}\text { 4. Formación técnica } \\
\text { 5. Educación de los sen- } \\
\text { tidos. }\end{array}\end{array}$ & $\begin{array}{l}\text { 5. Éxito profesional } \\
\text { 6. Cultura general. }\end{array}$ \\
\hline
\end{tabular}

El establecimiento de los fines educativos requiere una reflexión filosófica sobre el valor, importancia y jerarquía de los mismos de acuerdo a principios y criterios éticos y no puramente pragmáticos e ideológicos.

3.1.2 Misión de la educación en la era planetaria (según Edgar Morin)

La misión de la educación para la era planetaria es fortalecer las condiciones de posibilidad de la emergencia de una sociedad-mundo compuesta por ciudadanos protagonistas, consciente y críticamente comprometidos en la construcción de una civilización planetaria.

Esta misión debe comenzar realizando una acción institucional que permita incorporar en los distintos espacios educativos y de acuerdo a los diferentes niveles de aprendizaje seis ejes estratégicos directrices para 
una acción ciudadana articuladora de sus experiencias y conocimientos, y para una contextualización permanente de sus problemas fundamentales en la prosecución de la hominización.

Los seis ejes estratégicos directrices son los siguientes:

\section{El eje estratégico directriz conservador/revolucionante.}

Esta estrategia consiste en aprender a percibir y generar dos esfuerzos, dos acciones generalmente vistas como antagónicas excluyentes, pero que, para el pensamiento complejo, son antagonistas y complementarias. Es preciso promover las acciones conservadoras para fortalecer la capacidad de supervivencia de la humanidad y al mismo tiempo, es preciso promover las acciones revolucionantes inscritas en la continuación y el progreso de la hominización.

\section{El eje estratégico directriz para progresar resistiendo.}

Este eje estratégico consiste en orientar las actitudes de resistencia de la ciudadanía contra el retorno persistente y los despliegues de la barbarie. Esta barbarie a la que es preciso resistir estratégicamente, no es solamente aquella que nos acompaña desde los orígenes de la historia humana, sino también es la barbarie que surge de la alianza de aquella antigua barbarie de violencia, odio y dominación con las fuerzas modernas tecnoburocráticas, anónimas y congeladas de deshumanización y desnaturalización.

3. El eje estratégico directriz que permita problematizar y repensar el desarrollo y criticar la idea subdesarrollada de subdesarrollo

El desarrollo debe concebirse de forma antropológica porque el verdadero desarrollo es el desarrollo 
humano. Por lo tanto, la educación debe colaborar en el rescate de la idea de desarrollo del encuadre y la simplificación producido por el reduccionismo economicista. En este sentido, el desarrollo supone la ampliación de las autonomías individuales a la vez que el crecimiento de las participaciones comunitarias, desde las participaciones locales hasta las participaciones planetarias. Más libertad y más comunidad, más ego y menos egoísmo.

El subdesarrollo de los desarrollados es un subdesarrollo moral, psíquico e intelectual. Hay una miseria que no disminuye con el decrecimiento de la miseria fisiológica y material, sino que se acrecienta con la abundancia y el ocio.

Es preciso también que la educación colabore con los esfuerzos necesarios para repensar el desarrollo, que conduzcan a repensar críticamente la idea, también subdesarrollada de "subdesarrollo". Porque la idea de subdesarrollo ignora las eventuales virtudes y riquezas de las culturas milenarias de las que son/eran portadores los pueblos llamados subdesarrollados. Esta noción contribuye poderosamente a consagrar a la muerte a esas culturas, vistas como conjunto de supersticiones.

La educación debe fortalecer el respeto por las culturas, y comprender que ellas son imperfectas en sí mismas, como lo es el ser humano.

La disminución de la miseria mental de los desarrollados permitiría rápidamente, en nuestra era científica, resolver el problema de la miseria material de los subdesarrollados. Pero es justamente ese desarrollo mental el que no logramos superar porque no tenemos conciencia de él. Esto implica que en la prosecución de la hominización exista necesariamente una ética del desarrollo, sobre todo porque ya no hay una promesa y una certeza absoluta de una ley del progreso. 
Por último, en las finalidades anteriores es preciso incluir la búsqueda de la plenitud y la completitud del individuo, a través de la música, de la poesía, de la mística y de las artes en general, que exceden a los objetivos del desarrollo.

4. El eje estratégico directriz que permite el regreso (reinvención) del futuro y la reinvención (regreso) del pasado. Toda sociedad, todo individuo viven dialectizando la relación pasado/presente/futuro, donde cada término se alimenta de los otros.

En todas partes, la relación viviente pasado/presente/futuro se halla seca, atrofiada o bloqueada. Es preciso, en consecuencia, una revitalización de esa relación que respete las tres instancias sin la hipertrofia de ninguna de ellas.

La renovación y el aumento de la complejidad de la relación pasado/presente/futuro debería entonces inscribirse como una de las finalidades de la educación. Como decía San Agustín: "Hay tres tiempos: el presente del pasado, el presente del presente y el presente del futuro".

5. El eje estratégico directriz para la complejización de la política y para una política de la complejidad del devenir planetario de la humanidad.

La educación tendrá que facilitar la percepción y la critica de la falsa racionalidad de la política, es decir, la racionalidad abstracta y unidimensional inscrita en la seudofuncionalidad planificadora que no tiene en cuenta las necesidades no cuantificables y no identificables por las encuestas.

La inteligencia parcelada, compartimentada, mecanicista, desunida, reduccionista de la gestión política unidimensional destruye el complejo mundo en fragmentos desunidos, fracciona los problemas, separa lo que está unido, unidimensionaliza lo multidimensional. 
El pensamiento planetario deja de oponer lo universal y lo concreto, lo general y lo singular: lo universal se ha vuelto singular, es el universo cósmico y concreto, es el universo terrestre.

6. El eje estratégico directriz para civilizar la civilización.

La prosecución de la hominización, que daría lugar al abandono de la edad de hierro planetaria, nos incita a reformar la civilización occidental, que se ha planetarizado tanto en sus riquezas como en sus miserias, para llegar a la era de la civilización planetaria.

Como muestra la historia del siglo XX, la voluntad de instaurar la salvación sobre la tierra termina instalando un infierno. No habría que caer una vez más en el sueño de la salvación terrestre. Querer un mundo mejor, nuestra finalidad principal, no es querer el mejor de los mundos.

La civilización de la civilización demanda la construcción de una geopolítica.

Para tal fin, la educación tendrá que fortalecer las actitudes y aptitudes que permitan superar los obstáculos enquistados en la dinámica social producidos por las estructuras burocráticas y las institucionalizaciones de las políticas unidimensionales.

Nuestra cultura actual corresponde entonces a la prehistoria del espíritu humano y nuestra civilización corresponde a la presente edad de hierro planetaria.

\subsection{Implicaciones}

Las implicaciones educativas de ciertos planteamientos filosóficos permiten visualizar mejor las relaciones entre Educación y Filosofía. Veamos dos ejemplos ilustrativos: 


\begin{tabular}{|c|c|}
\hline Planteamientos & Implicaciones \\
\hline $\begin{array}{l}\text { 1. Verdad y } \\
\text { Conocimiento }\end{array}$ & $\begin{array}{l}\text { 1.1. Teorías cognitivas } \\
\text { 1.2. Modelos curriculares } \\
\text { 1.3. Teorías de aprendizaje. }\end{array}$ \\
\hline $\begin{array}{l}\text { 2.Subjetividad y } \\
\text { Objetividad }\end{array}$ & $\begin{array}{l}\text { 2.1. Metodología de la investigación } \\
\text { científica } \\
\text { 2.2. Teoría y metodologías de evaluación } \\
\text { 2.3. Educación en valores. }\end{array}$ \\
\hline
\end{tabular}

\section{Verdad y Conocimiento}

Vivimos en una cultura de "transiciones múltiples y certezas mínimas" (Federico Mayor) denominada "era posmoderna", en la que campea por doquier el relativismo, que no acepta "verdades absolutas". En esta era llamada también "sociedad del conocimiento" construye cada quien "su propia verdad", sin que nadie se preocupe más por la "búsqueda de la verdad" como tal. Se percibe en realidad mayor interés y preocupación por el conocimiento que por la verdad.

La Filosofía perenne ha acentuado siempre la importancia de la "verdad", que es superior al "conocimiento", porque "el conocer no es la finalidad de la existencia" (J. Gevaert) y "la búsqueda de la verdad está polarizada por la necesidad de encontrar un sentido a la existencia" (ídem). Esto significa que "verdad" y "sentido" son inseparables y que el "conocimiento" es un medio (excelente por cierto), pero supeditado a la "verdad", que es un fin en sí mismo. 
La mayor parte de las teorías actuales cognitivas, curriculares y de aprendizaje se ubican casi exclusivamente en el territorio del "conocimiento", propio de la cultura científico-técnica y poco en el campo de la "verdad", propio de la cultura humanista. En términos de Ladrière, se trata del predomino de la "racionalidad instrumental" sobre la "racionalidad ontológica".

Las consecuencias de esta postura filosófica para la educación de las nuevas generaciones son graves: "deshumanización" y "desnaturalización".

\section{Subjetividad y Objetividad}

En términos generales, la "Subjetividad" es la capacidad para percibir una realidad como la persona cree que es. La "Objetividad", en cambio, es la capacidad para percibir una realidad tal y como es.

La Filosofía Clásica y Medieval (Aristóteles, Santo Tomás de Aquino) prestaron especial atención al estudio de la "realidad objetiva". La Filosofía Moderna (Descartes, Kant, Hegel) se centró principalmente, en cambio, en la "realidad subjetiva".

La Filosofía Contemporánea, influenciada con fuerza por la Filosofía Existencialista (Kierkegaard, Jaspers, Heidegger), los conceptos de "Relatividad" (Einstein), "Incertidumbre" (Heisenberg), "Falsabilidad" (Popper), y, más recientemente, el "Pensamiento Complejo" (Morin) y la "Biología de la Educación" (Maturana), ha evitado progresivamente la polarización de estos términos, que ahora son vistos más bien como complementarios e interdependientes, aunque por influencia de las Neurociencias (Sperry, Eccles, Llinás) se halla más inclinada hacia la Subjetividad, pero una subjetividad-objetiva y una objetividad-subjetiva, expresada en las siguientes declaraciones: "No vemos la realidad como 
es, sino como somos", "el sujeto observador forma parte del objeto observado".

Esta nueva concepción filosófica de "lo subjetivo" y "lo objetivo" incide de manera decisiva en la valoración de las ciencias (ya no existen "ciencias de primera" y "ciencias de segunda" categoría) y de los métodos de investigación científica (métodos cualitativos y cuantitativos), así como en la formación en Ética y Valores, al permitir establecer una relación dialéctica entre "lo absoluto" y "lo relativo", "lo universal" y "lo particular", "lo científico" y "lo cultural” en el abordaje pedagógico de esta temática.

\section{CONCLUSIONES}

Sintesis de interacciones e implicaciones entre Filosofía y Educación

1. Es un hecho palmario que la Filosofía y la Educación han mantenido múltiples interacciones e implicaciones a lo largo de la Historia de la Filosofía y la Pedagogía en la cultura occidental, hasta el punto de poder hablar-simplificando- de un filosofar educando y educar filosofando.

2. Durante este tiempo, comprendido entre la Era Clásica (s. V a.C.) y la Era Planetaria (s. XXI d.C.), la Filosofía y la Educación han sostenido relaciones muy cercanas en grado e intensidad diferentes: al comienzo (época clásica y medieval) la Educación fue casi una rama de la Filosofía (Pedagogia ancilla Philosophiae et Philosophia ancilla Theologiae). A partir del Renacimiento (s. XV) y, sobre todo, de la Era Moderna (s. XVII-XIX), se invirtió la relación: la Filosofía se puso al servicio de la Educación (Philosophia ancilla Pedagogiae), al tiempo que la Educación empezó a emanciparse de la Filosofía y a asociarse más bien con 
las ciencias humanas (psicología, sociología, lingüística). Ya en la Era Contemporánea (s. XX), con el reconocimiento de la Filosofía y la Pedagogía como ciencias humanas, se inicia una relación más interdisciplinaria entre ambas (Philosophia socia Pedagogiae), claramente manifiesta en la disciplina "Filosofía de la Educación", que en la Era Planetaria (s. XXI) entran a formar parte del universo de las ciencias (universum scientiarum), con una relación mediada por las ciencias naturales (especialmente la Biología) y por las ciencias sociales (especialmente la Antropología y la Comunicación).

3. Existen implicaciones filosóficas en ciertos planteamientos educativos (por ejemplo, Formación, Aprendizaje, Disciplina...). Por eso, de una fuerte interacción entre Filosofía y Educación se ha pasado a una intensa implicación mutua a través de la Epistemología y la Hermenéutica, que establecen criterios de validez para las teorías y métodos de la Pedagogía Científica (Epistemología de la Pedagogía), pero que acepta también con respeto la autonomía, los principios y las leyes que regulan a las ciencias de la educación.

4. Existen además implicaciones educativas en ciertos planteamientos filosóficos (Filosofía de la Educación, Antropología de la Educación). La Educación tiene unos fines que deben ser fundamentados y jerarquizados de forma argumentada y coherente; deben responder también a las necesidades y exigencias de la sociedad planetaria.

5. Hay dos temas filosóficos que tienen profunda incidencia en la práctica educativa: la Verdad y el Conocimiento, la Subjetividad y la Objetividad. El primero reorienta la formación de las nuevas genera- 
ciones hacia un compromiso serio con la verdad, de donde se deriva la importancia de la formación del pensamiento crítico y autocrítico. El segundo permite ampliar el horizonte investigativo y asumir responsablemente un cuadro de valores para guiar la propia existencia.

\section{Notas}

1 Ponencia dictada en el Congreso de Filosofía y Pedagogía, del 12 al 14 de junio de 2007. Universidad Politécnica Salesiana-Quito.

\section{BIBLIOGRAFÍA}

ABRIL, M.

2004 Diccionario enciclopédico de Educación. Quito.

BEDOYA, I.-GÓMEZ, M.

1989 Epistemología y Pedagogía. Medellín.

BRAVO, N.

1997 Pedagogía Problémica. Acerca de los nuevos paradigmas en educación. Bogotá.

EISNER, E.

1994 Cognición y Curriculum. Buenos Aires.

FLÓREZ OCHOA, R.

1999 Evaluación pedagógica y Cognición. Bogotá.

FLÓREZ OCHOA, R.

2001 Investigación Educativa y Pedagógica. Bogotá.

GARCÍA AMILBURU, M.

1996 Aprendiendo a ser humanos. Una Antropología de la Educación. Navarra.

GEVAERT, J.

1984 El problema del hombre. Introducción a la Antropología Filosófica. Salamanca, .

HIRSCHBERGER, J.

1982 Historia de la Filosofía. Tomos 1 y II. Barcelona. 
KUHN, Th.

1972 La estructura de las revoluciones científicas. México.

MATURANA, $\mathrm{H}$.

1995 La realidad: ¿objetiva o construida? Barcelona.

MORALES, G.

2006 El Giro Cualitativo de la Educación. Cali.

MORALES, G.

2006 Cómo Educar hoy en Ética, Valores y Moral. Cali. MORENO, F.

1988 Revolución científica y formación humana en la universidad. Bogotá.

MORIN, E.

2001 Los siete saberes necesarios para la educación del futuro. Bogotá.

MORIN, E.

2006 Educar en la Era Planetaria. Barcelona.

RODRÍGUEZ, M.

1999 Creatividad para resolver problemas. Bogotá.

RÍOS, P.

2000 La Aventura de Aprender. Caracas. 